\title{
Pengaruh Perbandingan Jenis Buah (Terong Belanda Dan Bit) dan Konsentrasi Carboxy Methyl Cellulose (CMC) Terhadap Mutu Organoleptik Sorbet (The Influence of Fruit Types Comparison (Terong Belanda and Beetroot) and Carboxy Methyl Cellulose (CMC) Consentration as Stabilizer Towards Sensory Properties of Sorbet)
}

\author{
Nanda Supriana ${ }^{1}$, Dian Hasni ${ }^{1}$, Syarifah Rohaya ${ }^{1}$ \\ ${ }^{1}$ Program Studi Teknologi Hasil Pertanian, Fakultas Pertanian, Universitas Syiah Kuala
}

\begin{abstract}
Abstrak. Terong belanda merupakan buah berasa asam yang khas, namun memiliki warna yang kurang menarik. Disisi lain buah bit mempunyai warna yang menarik, karena pada buah bit terkandung pigmen betalain yang dapat menghasilkan warna merah dan ungu. Tujuan dari penelitian ini adalah untuk mengetahui pengaruh konsentrasi CMC dan penambahan buah terong belanda dan bit terhadap mutu organoleptik sorbet. Penelitian ini menggunakan Rancangan Acak Lengkap (RAL) dengan faktor perbandingan buah terong belanda dan bit $\left(\mathrm{P}_{1}=\right.$ $1: 1, \mathrm{P}_{2}=2: 1$ dan $\left.\mathrm{P}_{3}=3: 1\right)$ dan konsentrasi CMC $\left(\mathrm{C}_{1}=0 \%, \mathrm{C}_{2}=0,25 \%, \mathrm{C}_{3}=0,50 \%\right.$ dan $\left.\mathrm{C}_{4}=75 \%\right)$ dengan total 24 satuan percobaan. Hasil analisis menunjukkan penambahan proporsi terong belanda cenderung meningkatkan nilai organoleptik aroma dan rasa, sedangkan peningkatan konsentrasi CMC cenderung meningkatkan nilai organoleptik warna, rasa dan tekstur. Sorbet dengan perlakuan terbaik berdasarkan analisis keseluruhan diperoleh dengan menggunakan buah terong belanda:bit(2:1) dengan respon uji hedonik untuk warna 4,53 (agak suka), aroma 4,23 (netral), rasa 4,40 (agak suka) dan tekstur 4,63 (agak suka).
\end{abstract}

Kata kunci: Sorbet, terong belanda, buah bit, carboxy methyl cellulose, antioksidan.

\begin{abstract}
Terong belanda is a sour-taste typical fruit, but it has a less attractive color. On the other hand, beetroot has an interesting color because it contains betalain pigment producing red and purple colors. The purpose of this study was to determine the effect of CMC concentration and the addition of terong belanda and beetroot on the organoleptic quality of sorbet. This study used a Completely Randomized Design (CRD) with the ratio of terong belanda and beetroot factor $(\mathrm{P} 1=1: 1, \mathrm{P} 2=2: 1$ and $\mathrm{P} 3=3: 1)$ and $\mathrm{CMC}$ concentration factor $(\mathrm{C} 1$ $=0 \%, \mathrm{C} 2=0.25 \%, \mathrm{C} 3=0.50 \%$ and $\mathrm{C} 4=75 \%$ ) with two replicates creating a total of 24 experimental units. The results showed that the addition of terong belanda tended to increase the proportion of aroma and taste organoleptic values, while the increase in the concentration of CMC tended to improve the color, taste and texture organoleptic values. The best Sorbet was obtained using the ratio of terong belanda and beetroot $(2: 1)$ having the following hedonic characteristics: 4.53 (a bit like) color, 4.23 (neutral) aroma, 4.40 (rather like) flavor and 4.63 (a bit like) texture.
\end{abstract}

Keywords: Sorbet, terong belanda, beetroot, carboxy methyl cellulose, antioxidant.

\section{PENDAHULUAN}

Sorbet merupakan frozen dessert yang terbuat dari sari buah-buahan segar dengan campuran air, sukrosa dan bahan penstabil. Sorbet memiliki potensi untuk meningkatkan nilai ekonomis produk turunan buah, seperti terong belanda dan bit. Penggunaan terong belanda dan bit dalam penelitian ini sebagai bahan baku dalam pembuatan sorbet, karena buah terong belanda mempunyai banyak kandungan antioksidan berasa asam namun dengan warna gelap, sedangkan buah bit agar diperoleh sorbet dengan warna yang menarik, karena pada buah bit terkandung betalain yang akan menghasilkan warna merah dan ungu. Pada pembuatan sorbet juga digunakan CMC (Carboxy Methyl Cellulose) sebagai penstabil. Penelitian ini bertujuan untuk mengetahui pengaruh konsentrasi CMC dan penambahan buah 
terong belanda dan bit terhadap mutu organoleptik sorbet dari buah terong belanda (Cyphomandra betacea. S) dan bit (Beta vulgaris).

Standarisasi mutu tidak selamanya menggunakan kriteria mutu objektif. Pada banyak komoditas disamping kriteria objektif digunakan pula kriteria mutu organoleptik. Sifat-sifat mutu organoleptik yang sering dijadikan mutu adalah warna, aroma, rasa dan tekstur (Soekarto, 1990). Parameter organoleptik yang memberikan kesan pertama untuk panelis adalah warna dari suatu produk, karena menggunakan indera penglihatan. Menarik atau tidaknya suatu produk untuk dikonsumsi dapat dilihat dari warnanya (Winarno, 1997).

\section{METODE PENELITIAN}

Penelitian ini telah dilaksanakan pada bulan April -Mei 2016. Penelitian ini dilakukan di Laboratorium Pengolahan Nabati dan Laboratorium Organoleptik Jurusan Teknologi Hasil Pertanian Universitas Syiah Kuala Banda Aceh.

\section{MATERI DAN METODE}

\section{Sorbet}

Bahan yang digunakan dalam pembuatan sorbet adalah buah terong belanda yang berwarna kemerahan dan buah bit yang berwarna ungu tua yang diperoleh di Pasar Tradisional Peunayong, Banda Aceh, CMC dan gula.

Alat yang dibutuhkan dalam pembuatan sorbet yaitu wadah plastik, saringan, blender, freezer dan ice cream maker. Alat yang dibutuhkan untuk analisis organoleptik sorbet adalah kertas label, cup plastik kecil dan sendok plastik kecil.

\section{Metode Penelitian}

Buah terong belanda dan buah bit masing-masing dibersihkan dan diblender dengan perbandingan 1:1, kemudian disaring dengan menggunakan saringan. Sari buah terong belanda dan buah bit dicampurkan dengan perbandingan 1:1, 2:1 dan 3:1. Ditambahkan CMC sesuai dengan taraf perlakuan $(0 \%, 0,25 \%, 0,50 \%$ dan $0,75 \%)$ dan gula $15 \%$ lalu didinginkan dalam refrigerator selama 1 jam. Kemudian dibekukan dalam ice cream maker selama 30 menit dan dibekukan dalam freezer untuk selanjutnya dilakukan analisis organoleptik.

\section{Uji Organoleptik}

Uji organoleptik yang dilakukan adalah uji hedonik (kesukaan) yang merupakan pengujian sensori untuk menentukan tingkat penerimaan panelis terhadap suatu produk dengan menggunakan indera penglihat, pencium, perasa dan peraba. Pada penelitian ini digunakan skala angka dengan nilai sensori ( $1=$ sangat tidak suka), ( $2=$ tidak suka), ( $3=a g a k$ tidak suka), (4=netral), (5=agak suka). ( $6=$ suka $),(7=$ sangat suka). Parameter yang diamati adalah warna, aroma, rasa dan tekstur. (Karlina,2008).

\section{Analisa Statistik}

Penelitian ini menggunakan Rancangan Acak Lengkap (RAL) yang terdiri dari 2 faktor yaitu perbandingan buah terong belanda dan bit $\left(\mathrm{P}_{1}=1: 1, \mathrm{P}_{2}=2: 1\right.$ dan $\left.\mathrm{P}_{3}=3: 1\right)$ dan konsentrasi CMC (Carboxy Methyl Cellulose) $\left(\mathrm{C}_{1}=0 \%, \mathrm{C}_{2}=0,25 \%, \mathrm{C}_{3}=0,50 \%\right.$ dan $\mathrm{C}_{4}=$ $75 \%$ ) dengan total 24 satuan percobaan. Data yang diperoleh dianalisa dengan analisis 
keragaman (ANOVA) dan perlakuan yang memberikan pengaruh yang berbeda nyata atau sangat nyata dilakukan uji lanjut dengan uji Beda Nyata Terkecil (BNT).

\section{HASIL DAN PEMBAHASAN}

\section{Organoleptik Warna}

Nilai uji hedonik warna sorbet yang dihasilkan berkisar antara 3,43 - 5,43 (agak tidak suka hingga agak suka) dengan rata-rata 4,69 (agak suka). Perbandingan buah dan konsentrasi CMC berpengaruh sangat nyata $(\mathrm{P} \leq 0,01)$ sedangkan interaksi perlakuan perbandingan buah dan konsentrasi $\mathrm{CMC}$ berpengaruh nyata $(\mathrm{P} \leq 0,05)$ terhadap organoleptik warna sorbet.

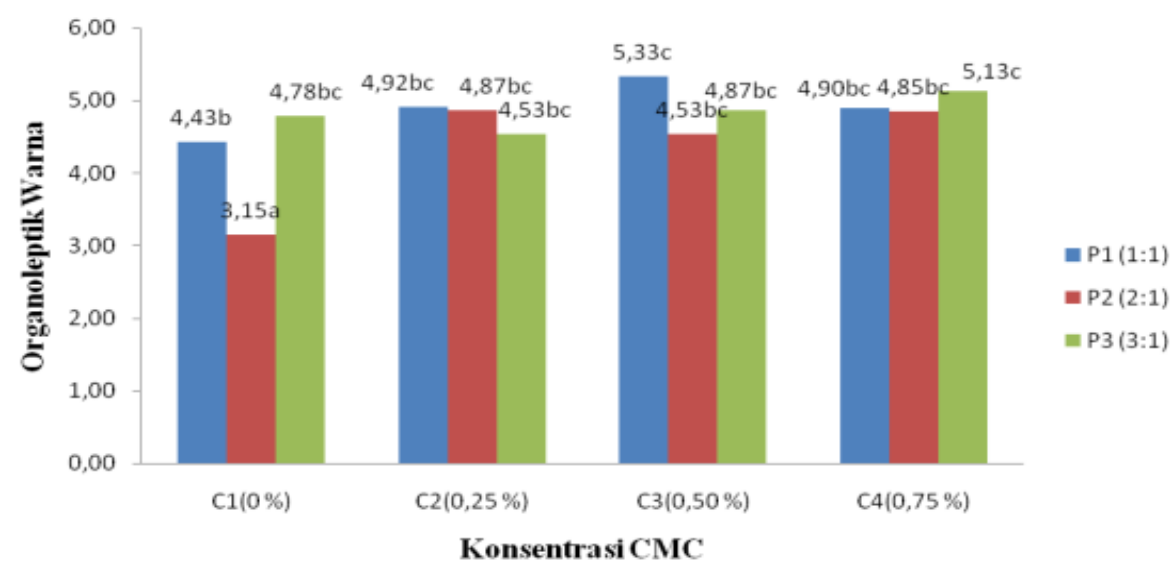

Gambar 1. Pengaruh interaksi perbandingan buah terong belanda dan bit serta konsentrasi $\mathrm{CMC}$ terhadap organoleptik warna $\left(\mathrm{BNT}_{0,05}=0,63, \mathrm{KK}=6,23 \%\right)$.

Perlakuan terong belanda : bit (1:1), uji kesukaan warna yang tinggi diperoleh pada sorbet yang menggunakan konsentrasi CMC 0,50\% dengan nilai 5,33 (agak suka), sedangkan uji hedonik warna terendah diperoleh dari perlakuan terong belanda : bit (1:1) tanpa CMC dengan nilai 4,43 (agak suka). Pada perlakuan terong belanda : bit (2:1), uji kesukaan warna yang tinggi diperoleh pada sorbet yang menggunakan konsentrasi CMC 0,25\% dengan nilai yang diperoleh 4,87 (agak suka), sedangkan uji kesukaan warna terendah diperoleh tanpa menggunakan CMC dengan nilai 3,15 (agak tidak suka).

Perlakuan terong belanda : bit (3:1), uji kesukaan warna yang tinggi diperoleh pada sorbet yang menggunakan konsentrasi CMC 0,75\% dengan nilai yang diperoleh 5,13 (agak suka), sedangkan uji kesukaan warna rendah diperoleh pada sorbet yang menggunakan CMC 0,25\% dengan nilai 4,53 (agak suka). CMC merupakan jenis penstabil dengan daya ikat yang kuat, sehingga dapat mempertahankan zat warna dari sorbet (Silalahi dkk., 2014). Selain itu CMC bersifat inert, yang berarti tidak bereaksi dengan zat yang lain sehingga warna sorbet tetap terlihat kemerahan (Kamal, 2010).

\section{Organoleptik Aroma}

Aroma sorbet yang dihasilkan berkisar antara 3,36 - 4,73 (agak tidak suka hingga agak suka) dengan rata-rata 4,10 (netral). Perbandingan buah berpengaruh nyata $(\mathrm{P} \leq 0,05$, sedangkan konsentrasi CMC dan interaksi perlakuan perbandingan buah dan konsentrasi CMC berpengaruh sangat nyata $(\mathrm{P} \leq 0,01)$ terhadap nilai uji organoleptik aroma sorbet. 


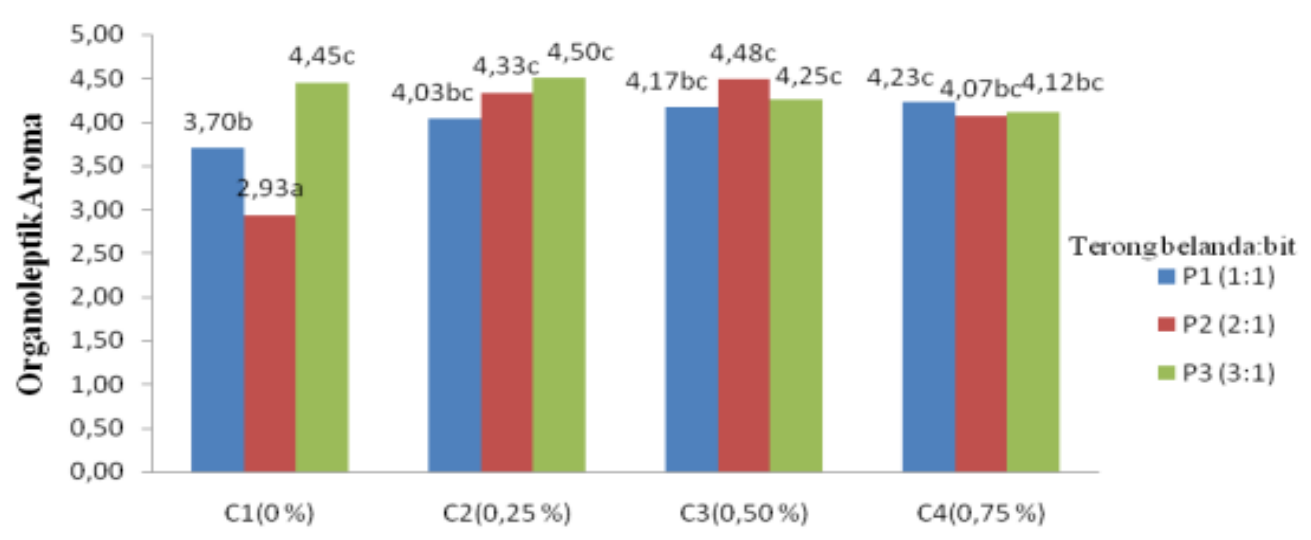

Konsentrasi CMC

Gambar 2. Pengaruh interaksi perbandingan buah dan konsentrasi CMC terhadap organoleptik aroma $\left(\mathrm{BNT}_{0,05}=0,51, \mathrm{KK}=5,72 \%\right)$.

Perlakuan terong belanda:bit (1:1) tanpa menggunakan CMC memiliki nilai hedonik aroma tinggi 4,45 (agak suka), sedangkan uji kesukaan aroma rendah tanpa menggunakan CMC dengan nilai 2,93 (netral) yang berbeda nyata satu dengan lainnya. Gambar 10 menunjukkan peningkatan proporsi terong belanda dan buah bit hingga 3:1 cenderung meningkatkan nilai hedonik aroma, baik tanpa cmc atau dengan penambahan CMC hingga $0,50 \%$. Hal ini diduga karena semakin banyak jumlah proporsi terong belanda yang digunakan, semakin banyak komponen asam organik terong belanda di dalam sorbet sehingga aroma khas terong belanda semakin kuat.

\section{Organoleptik Rasa}

Nilai uji hedonik rasa sorbet yang dihasilkan berkisar antara 3,10-4,66 (agak tidak suka hingga agak suka) dengan rata-rata 4,12 (netral). Perbandingan buah dan konsentrasi $\mathrm{CMC}$ berpengaruh nyata $(\mathrm{P} \leq 0,05)$ terhadap nilai uji organoleptik rasa sorbet.

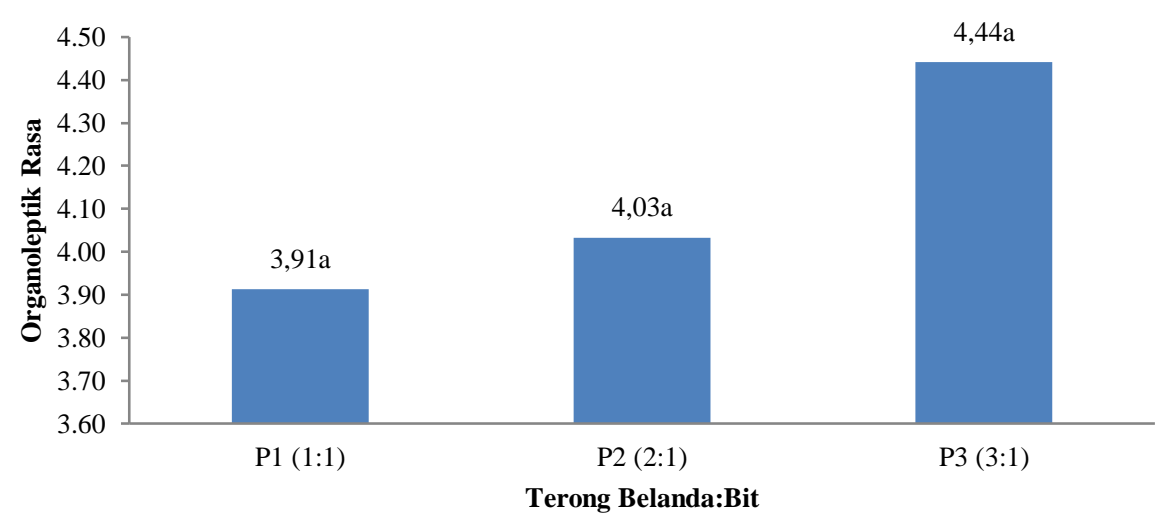

Gambar 3. Pengaruh perbandingan buah terong belanda dan bit terhadap organoleptik rasa $\left(\mathrm{BNT}_{0,05}=0,70\right.$, $\mathrm{KK}=7,79 \%)$.

Gambar 3 menunjukkan peningkatan proporsi terong belanda cenderung meningkatkan nilai hedonik rasa, namun setiap taraf perlakuan berbeda tidak nyata satu sama lainnya dengan kisaran nilai hedonik 3,91 - 4,44 (netral hingga agak suka). Penerimaan organoleptik rasa diduga akibat tingginya kandungan asam buah yang kemungkinan berdampak pada adanya rasa asam khas buah terong belanda yang disukai oleh panelis. Selain itu buah bit memiliki 
rasa hambar dengan sedikit rasa manis dan aroma tanah yang kurang disukai, sehingga semakin banyak proporsi buah terong belanda yang digunakan, maka semakin disukai oleh panelis (Widyaningrum dan Suhartiningsih, 2014).

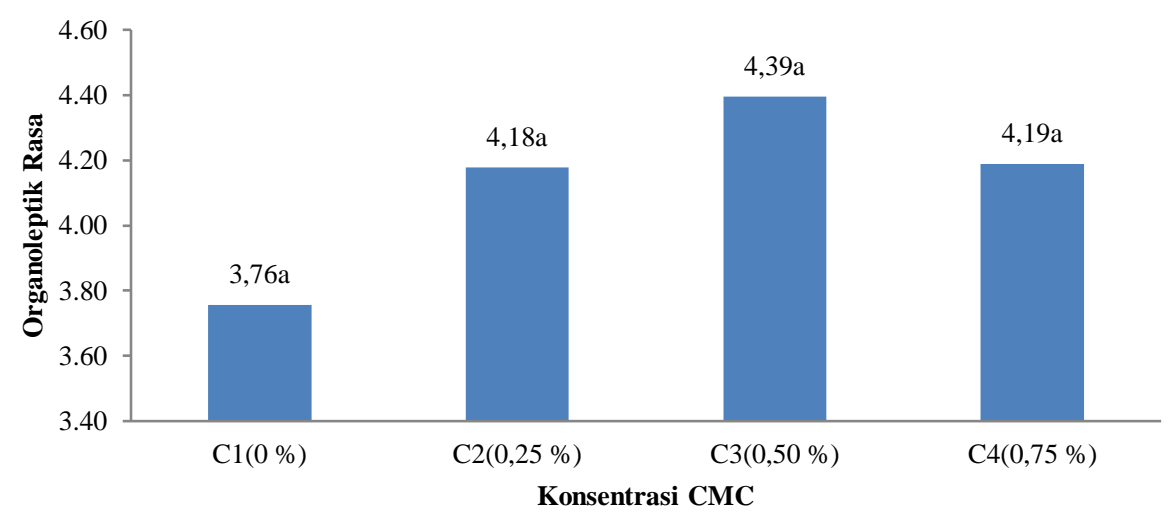

Gambar 4. Pengaruh konsentrasi CMC terhadap organoleptik rasa $\left(\mathrm{BNT}_{0,05}=0,81, \mathrm{KK}=7,79 \%\right)$.

Gambar 4 menunjukkan peningkatan penggunaan CMC cenderung meningkatkan nilai hedonik rasa, tetapi konsentrasi CMC 0,75\%, nilai hedonik rasa cenderung menurun. Hal ini diduga, karena konsentrasi CMC 0,75 \% membuat tekstur sorbet terlalu kental, sehingga kurang disukai oleh panelis. Alasan ini juga didukung dengan cenderung menurunnya nilai hedonik tekstur sorbet pada konsentrasi CMC 0,75\%.

\section{Organoleptik Tekstur}

Nilai uji hedonik pada tekstur sorbet yang dihasilkan berkisar antara 3,46-5,06 (agak tidak suka hingga agak suka) dengan rata-rata 4,34 (netral). uji hedonik tekstur sorbet menunjukkan bahwa konsentrasi $\mathrm{CMC}$ berpengaruh sangat nyata $(\mathrm{P} \leq 0,01)$ terhadap nilai uji organoleptik tekstur sorbet.

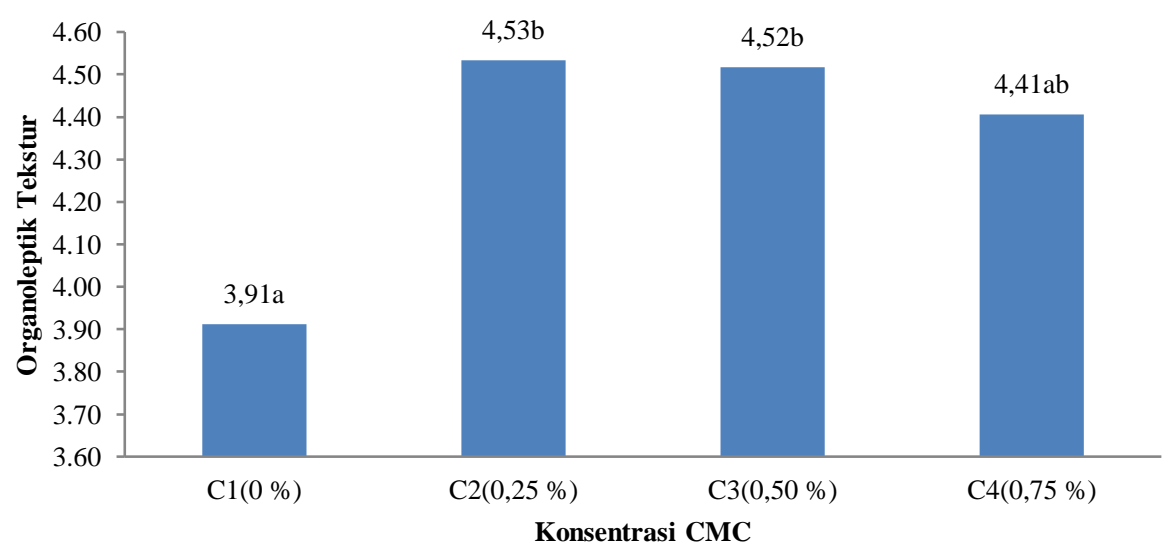

Gambar 5. Pengaruh konsentrasi CMC terhadap organoleptik tekstur $\left(\mathrm{BNT}_{0,05}=0,70, \mathrm{KK}=6,41 \%\right)$.

Gambar 5 menunjukkan bahwa peningkatan konsentrasi CMC cenderung meningkatkan nilai hedonik tekstur, hal ini sesuai dengan nilai waktu lelehan dan overrun yang cenderung meningkat seiring dengan semakin tinggi konsentrasi CMC yang digunakan, sehingga 
dihasilkan sorbet yang memiliki tekstur yang mengembang dengan kekentalan yang diterima dengan baik oleh panelis. Sedangkan konsentrasi CMC 0,50\% dan 0,75\% nilai hedonik tekstur cenderung menurun, karena menghasilkan sorbet yang bertekstur lebih kental.

\section{KESIMPULAN DAN SARAN}

Pengaruh penambahan konsentrasi CMC berpengaruh terhadap hedonik rasa, warna, aroma dan tekstur. Pengaruh perbandingan buah terong belanda : bit berpengaruh terhadap hedonik aroma, rasa dan warna. Interaksi antara konsentrasi CMC dan perbandingan buah terong belanda : bit berpengaruh terhadap hedonik warna dan aroma. Perlakuan terbaik berdasarkan analisis keseluruhan diperoleh dengan menggunakan buah terong belanda:bit (2:1) respon uji hedonik untuk warna 4,53 (agak suka), aroma 4,23 (netral), rasa 4,40 (agak suka) dan tekstur 4,63 (agak suka). Perlu adanya penelitian lebih lanjut mengenai pembuatan buah bit dengan konsentrasi yang lebih tinggi. Perlu adanya penelitian lanjutan pembuatan sorbet menggunakan air rebusan buah bit sebagai pewarna.

\section{DAFTAR PUSTAKA}

Astawan, M. dan L.K. Andreas. 1997. Khasiat Warna-Warni Makanan. PT Gramedia Pustaka Utama, Jakarta.

Kamal, N. 2010. Pengaruh Bahan Aditif CMC (Carboxyl Methyl Cellulose) Terhadap Beberapa Parameter Pada Larutan Sukrosa. Jurnal Teknologi. Vol 1 No. 2 : 78-84.

Karlina. 2008. Pemanfaatan Jahe (Zingiberis officinale Rose) dan Teh Hijau (Camellia sinensis) dalam Pembuatan Selai Rendah Kalori dan Sumber Antioksidan. Skripsi. Institut Pertanian Bogor, Bogor.

Silalahi, R.C., I. Suhaidi dan L.N. Limbong. 2014. Pengaruh Perbandingan Sari Buah Sirsak Dengan Markisa dan Konsentrasi Gum Arab Terhadap Mutu Sorbet Air Kelapa. Program Studi Ilmu dan Teknologi Pangan Fakultas Pertanian USU Medan. Jurnal Rekayasa Pangan dan Pertanian. Vol.2 No.2 : 26-34.

Soekarto, S. T. 1990. Dasar-Dasar Pengawasan dan Standarisasi Mutu Pangan. IPB, Bogor.

Widyaningrum, M. L. dan Suhartiningsih. 2014. Pengaruh Penambahan Puree Bit (Beta vulgaris) Terhadap Sifat Organoleptik Kerupuk. E-Journal Boga. Vol 3 No. 1 : 233238.

Winarno, F.G. 1997. Kimia Pangan dan Gizi. PT. Gramedia Pustaka Utama, Jakarta. 